\title{
A Reduction-of-Area Gage for Use at Low Temperatures
}

\author{
By Glenn W. Geil and Nesbit L. Carwile
}

\begin{abstract}
A reduction-of-area gage for measuring the change in diameter of cylindrical or notched tension specimens during tests at controlled temperatures is described. The gage was designed especially for use in tests of specimens completely submerged in a temperature-controlled bath at temperatures ranging from $-196^{\circ}$ to $+100^{\circ} \mathrm{C}$. The calibration of this gage showed that measurements can be made with an accuracy of 0.0001 inch. Some results obtained with the use of this gage are illustrated by true stress-true strain curves for annealed ingot iron, cold-worked nickel and cold-worked 18:8 chromium nickel steel tested in tension at $-188^{\circ}$ and $-196^{\circ} \mathrm{C}$.
\end{abstract}

\section{Introduction}

During the course of an investigation of the mechanical properties of metals at low and moderately elevated temperatures, it became evident that an instrument was needed that could be used to measure accurately the change in diameter of cylindrical specimens submerged in liquid baths during tension tests at various temperatures. The portion of the true stress-true strain curve from maximum load to fracture cannot be determined from extension measurements. Moreover, for some metals, an accurate determination of the curve from yield to maximum load cannot be made from extension measurements, as the metal may contract locally before reaching the maximum load. Simultaneous load and diameter measurements are essential for the determination of the complete true stress-true strain curves for metals tested in tension, as pointed out by MacGregor. ${ }^{1}$

Ordinary reduction of area gages cannot be used satisfactorily on specimens submerged in liquid baths. The photographic method described by Seigle ${ }^{2}$ for determining the change in diameter of a specimen submerged in a liquid bath during a tension test at low temperature was unsatisfactory at temperatures below $-130^{\circ} \mathrm{C}$. The reported accuracy of 0.0007 in. from the

\footnotetext{
1 C. W. MacGregor, Proc. Am. Soc. Testing Mat. 40, 508 (1940).

${ }^{2}$ L. Seigle, Effect of ferritic grain size on the true stress-strain tensile properties and notched impact strength of ingot iron at low temperatures, a thesis presented to the graduate school, University of Pennsyivania (1948).
}

photographs obtained under the most favorable conditions is considered inadequate. It was deemed advisable to design a mechanical gage suitable for use in the temperature range of $-196^{\circ}$ to $100^{\circ} \mathrm{C}$.

\section{Design of the Gage}

The reduction-of-area gage is shown in figure 1. The change in diameter of the test specimen during a tension test is followed by the movement of the sliding anvil, $A$, which is held against the specimen with slight pressure exerted by the tension spring, $F$. The movement of this anvil is transmitted to the spindle of the dial indicator by means of the simple lever, $B$. The pivot, or fulcrum, of this lever is a knife edge located at position $C$ (not visible in fig. 1). To maintain the lever in position, it is supported by the four flexure strips, $D$. These thin strips are sufficiently flexible to permit rotation of the lever about the knife edge through an angle considerably greater than that required to follow the change in diameter of the test specimen. The two guide bars, $E$, are adjusted to give a clearance of $0.01 \mathrm{in}$. to the lever, $B$, and serve to hold the lever in position and prevent any excessive twisting of the flexure strips while the instrument is not in use. A lubricated bearing, such as roller or ball bearings or a sleeve type bearing, could not be used as the fulcrum for the lever as this portion of the instrument is submerged in the temperature-controlled liquid bath. 


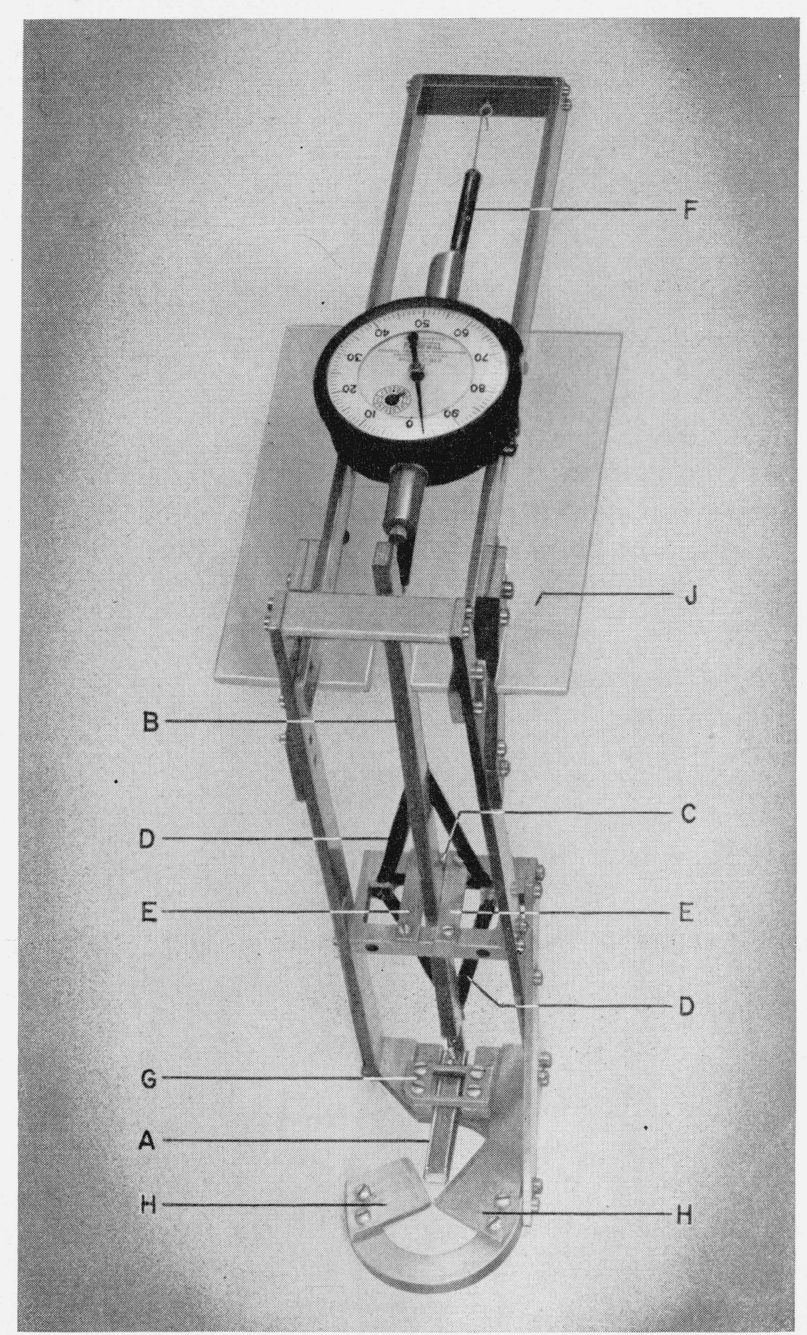

Figure 1. Reduction of area gage; $\times 0.4$

\begin{tabular}{|c|c|c|c|}
\hline $\begin{array}{l}\text { Desig- } \\
\text { nation }\end{array}$ & Part & Material & Remarks \\
\hline A. & Sliding anvil .... & SAE 52100 & Hardness of Re 63 . \\
\hline B & Lever & AISI $440-C_{-}$ & Hardness of Re 55. \\
\hline $\mathrm{C}_{-}$ & Pivot ........ & AISI $440-C_{-}$ & Hardness of Re 55. \\
\hline $\mathrm{D}_{-}$ & Flexure strips... & Phosphor bronze.. & $\begin{array}{l}\text { Cold rolled 0.003-in. } \\
\text { sheet. }\end{array}$ \\
\hline $\mathrm{E}_{--}$ & Guide bars $\ldots . . . .$. & Monel . . . & Cold rolled. \\
\hline $\mathrm{F}_{\ldots}$ & Tension spring.- & Phosphor bronze.. & Cold drawn. \\
\hline $\mathrm{G}_{-. .}$ & Retainer caps ... & Monel ............ & Cold rolled. \\
\hline $\mathrm{H}_{\ldots . . .}$ & Fixed anvils . ... & SAE $52100 \ldots$ & Hardness of Rc 63 . \\
\hline $\mathrm{J}_{-}$ & Shield & Plastic & \\
\hline
\end{tabular}

An enlarged view of the measuring anvils is shown in figure 2. The six ribs (two each on top and bottom and one on each side) on the sliding anvil serve as the bearing surfaces. To minimize the area of contact of the bearing surfaces, the ribs of the retainer caps, $G$, are at right angles to the direction of movement of the anvil, $A$. A clearance of 0.002 in. between these caps and the sliding anvil is sufficient to allow for unequal contraction of the component parts on cooling to low temperatures.

The sliding anvil is attached to the lever arm with a small tension spring, $I$, to facilitate installation of the gage on the tensile specimen while immersed in the liquid bath. The anchor pin, $K$, for this spring also serves as a stop against the retainer caps, $G$, to prevent the measuring edge of the sliding anvil hitting the contact edges of the fixed anvils, $H$, when the tensile specimen breaks. Both ends of the sliding anvil and the contact ends of the fixed anvils were machined to a dihedral angle of $50^{\circ}$ and a radius of $0.02 \mathrm{in.} \mathrm{This} \mathrm{design}$ provides for the free access of the measuring contact edges of the anvils to the minimum diameter portion of the necked section of the tensile specimen.

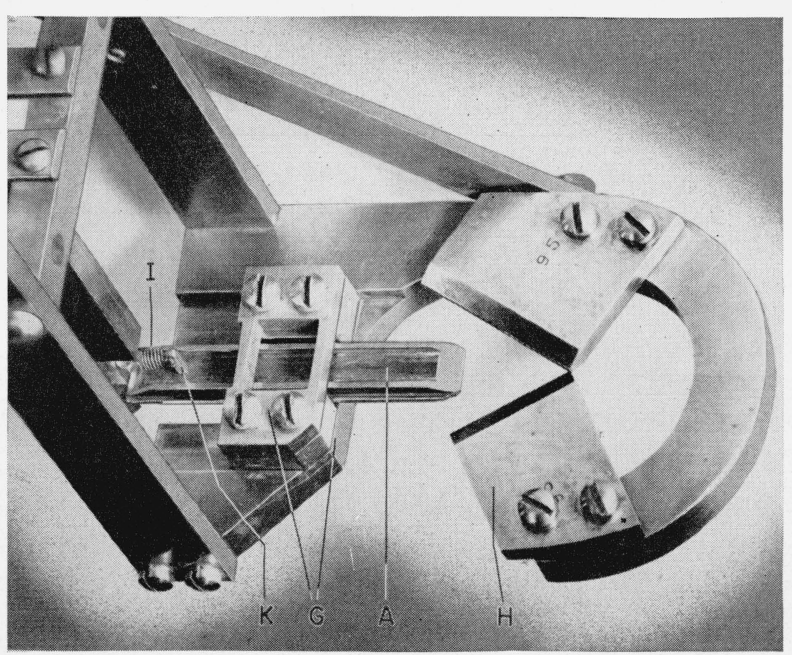

Figure 2. Design of the sliding and fixed anvils of the reduction of area gage.

\begin{tabular}{|c|c|c|c|}
\hline $\begin{array}{l}\text { Desig- } \\
\text { nation }\end{array}$ & Part & Material & Remarks \\
\hline A. & Sliding anvil_.... & SAE $52100_{-}$ & Hardness of Re 63 \\
\hline $\mathrm{H}_{-\ldots}$ & Fixed anvils & SAE $52100_{-}$ & Hardness of Re 63 \\
\hline $\mathrm{G}_{\ldots}$ & Retainer caps... & Monel_.... & Cold rolled \\
\hline $\mathrm{I}_{-\ldots}$ & Tension spring -- & Phosphor bronze_- & Cold drawn \\
\hline $\mathrm{K}_{-}$ & Anchor pin & Monel_............ & Cold rolled \\
\hline
\end{tabular}

The contact edges of the anvils are co-planar and at an angle of $60^{\circ}$ to each other. With this arrangement, the movement of the sliding anvil is 1.5 times the change in diameter of the test 
specimen. The length of the lever arm between the pivot knife edge and the anvil knife edge is approximately $2.5 \mathrm{in}$.; the length of the lever arm between the pivot knife edge and the contact point of the dial indicator is approximately 5 in. Thus the total magnification of the instrument is approximately 3 , or actually 2.985 , by calibration.

The dial indicator is a jeweled low-friction type indicator and is mounted on the framework so that it is adjustable. The choice of the dial indicator depends upon the ductility of the metal to be tested. If the ductility is very low, a dial indicator with a small range of approximately 0.25 in. and dial divisions to $0.0001 \mathrm{in}$. can be used. If the metal to be tested has high ductility, a dial indicator with a range of approximately $1 \mathrm{in}$. is required in order to follow the larger change in diameter of the specimen.

The anvils are made of SAE 52100 steel, and the lever and pivot knife edge are made of AISI type 440C stainless steel, heat-treated for hardness values of Rockwell $\mathrm{C} 63$ and C55, respectively. The flexure strips and the tension springs are phosphor bronze. The framework of the instrument is constructed of cold-rolled Monel, which has suitable corrosion resistance and strength. A plastic shield, $J$, is used to insulate the dial indicator from the vapors of the temperature-controlled liquid baths, and it also serves as a convenient handle for manipulation of the instrument.

\section{Calibration of the Gage}

The gage was calibrated at room temperature to check the linearity of the dial readings with diameters. A series of six cylindrical test standards, each machined with a circumferential groove of 0.03 -in. radius, were measured with an optical comparator to an accuracy of 0.0001 in. The diameters of the standards ranged from 0.1484 to 0.4864 in. The dial readings, obtained with the test standards, were plotted against the diameters of the test standards, and a linear relationship was obtained throughout the entire range. The slope of this line is equal to the magnification factor of the instrument and, as mentioned previously, is 2.985 . The zero reading of the instrument, $R_{0}$, is obtained by determining the dial reading at the intercept of this straight line with the zero diameter axis of the graph. The actual diameter, measurement $D$, for any reading is given by the following equation:
$D=\left(R_{0}-R\right) / F$, in which $R_{0}$ represents the zero reading, $R$ the actual dial reading, and $F$ the magnification factor for the instrument. The diameters obtained from the dial readings of this gage on the test standards were identical, to the nearest $0.0001 \mathrm{in}$., with the diameter measurements obtained with the optical comparator.

The instrument was also calibrated under simulated test conditions to obtain the temperature correction curve. Test standards of fused quartz were used. The standard was placed in position in the gage and the diameter reading obtained at room temperature. The gage and specimen then were placed in the temperature-controlled liquid bath and submerged to the depth at which the gage is used during a tension test. Diameter readings were taken after temperature equilibrium was attained. The time to reach temperature equilibrium ranged from 10 to $15 \mathrm{~min}$., and observations for greater periods up to 1 hour showed no further changes in the diameter readings. Calibration tests were made at $+100^{\circ},+27^{\circ},-78^{\circ}$, $-120^{\circ}$, and $-196^{\circ} \mathrm{C}$. Because of the very small coefficient of thermal expansion of fused quartz, the change in diameter of the quartz test standard did not exceed 0.00003 in. Therefore the changes in the dial readings were attributed to dimensional changes in the instrument. Data showing the relation between temperature and the indicated correction to be applied to the diameter measurement are shown in figure 3 .

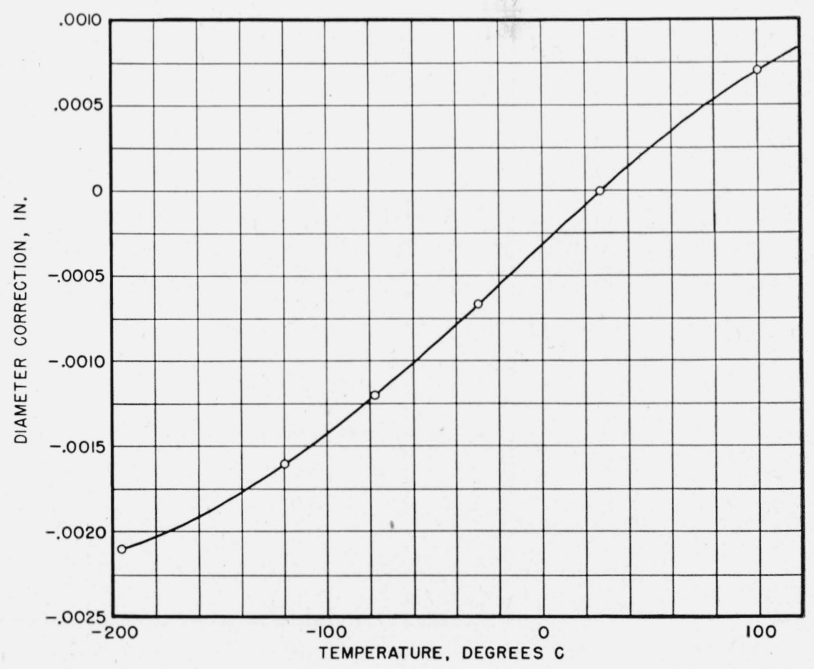

Figure 3. Curve for the gage showing the relation between the diameter corrections and the temperature.

The dial reading corrections are 2.985 times the diameter corrections. 
The change in the observed dial readings is 2.985 times the correction (actual diameter values) shown in this figure.

\section{Applications of the Gage}

The manipulation of this gage to determine the change in diameter of an unnotched cylindrical specimen during a tension test at low or moderately elevated temperatures is very simple. The test specimen supported vertically between the adapters of the tensile-testing machine is completely submerged in the temperature-controlled liquid bath. The gage is placed in position on the specimen with the measuring anvils at any position along the gage length of the specimen, and a time interval of about $15 \mathrm{~min}$. is allowed for the gage to come to temperature equilibrium. The alinement of the gage with respect to the specimen is adjusted until a minimum diameter reading is obtained, indicating that the plane of the measuring anvils is perpendicular to the axis of the specimen. While maintaining this alinement, the gage, supported by hand, is moved up and down through the gage length of the test specimen to find the diameter at the area of minimum cross section. Numerous simultaneous load and diameter readings are made during the tension test.

This gage also can be used for following the change in diameter of circumferentially notched cylindrical specimens during test in tension at low or moderately elevated temperatures. For this purpose a set of anvils is required in which the measuring edges are machined to an angle less than the smallest notch angle of the test specimens. The radius of the measuring edges of the anvils likewise must be less than the smallest radius at the root of the notch.

An example of the use of this gage in following the change in diameter of a metal specimen that has very little ductility at low temperature is illustrated in figure 4. This figure summarizes the results obtained in a tension test at $-196^{\circ} \mathrm{C}$ with

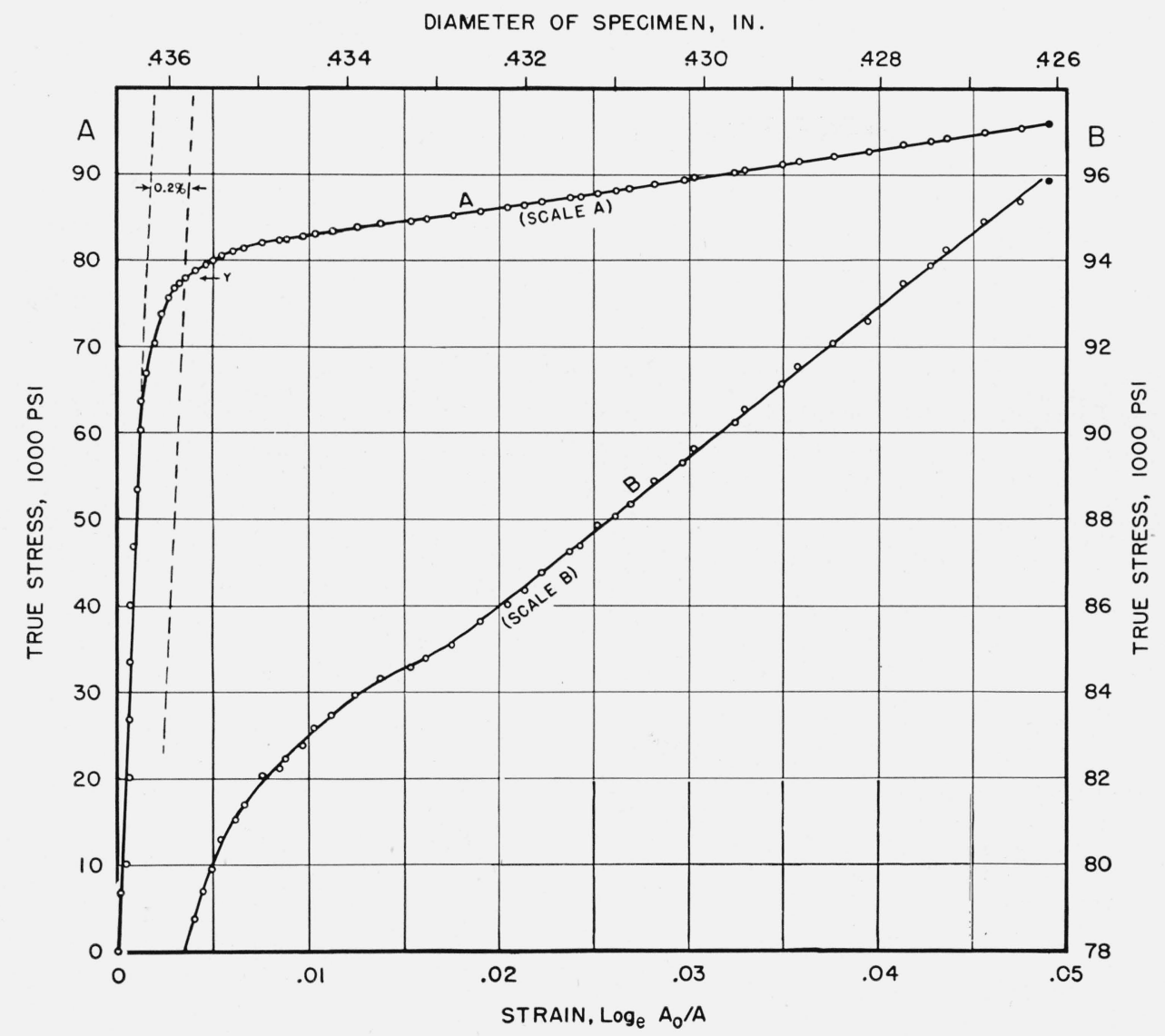

FIguRE 4. True stress-strain curves for a specimen of annealed ingot iron tested in tension at --196 ${ }^{\circ}$.

A, Complete true stress-true curve; B, portion of the true stress-true strain curve from yield to fracture on a more open stress scale. Y, Yield strength, 0.2-percent offset (reduction of area); $\mathbf{0}$, fracture. 
a cylindrical tensile specimen of annealed ingot iron. The true stress is plotted against the true strain. The true stress is the current load divided by the current minimum cross-sectional area, and the true strain is the $\log _{e}\left(A_{0} / A\right)$, in which $A_{0}$ and $A$ represent the initial and current minimum crosssectional areas, respectively. Curve $A$ is the entire true stress-true strain curve for this specimen. The portion of curve $A$ extending from yield to fracture is replotted on an expanded stress scale as curve $B$. The maximum deviation of any point from the curve corresponds to a change in diameter of the specimen of less than $0.0001 \mathrm{in}$. The bulge in the lower portion of curve $B$ is connected with a tendency to a drop of beam at yielding for the initially annealed ingot iron at this temperature.

An example of a complete true stress-true strain curve obtainable by the use of this instrument in a tension test in which the metal retains high ductility at low temperatures and contracts locally after reaching the maximum load is illustrated in figure 5. This figure shows the results obtained in a tension test at $-188^{\circ} \mathrm{C}$ with a cylindrical test specimen of nickel $(99.4 \% \mathrm{Ni})$ that had received prior cold work by extending in tension to a 25 -percent reduction of area.

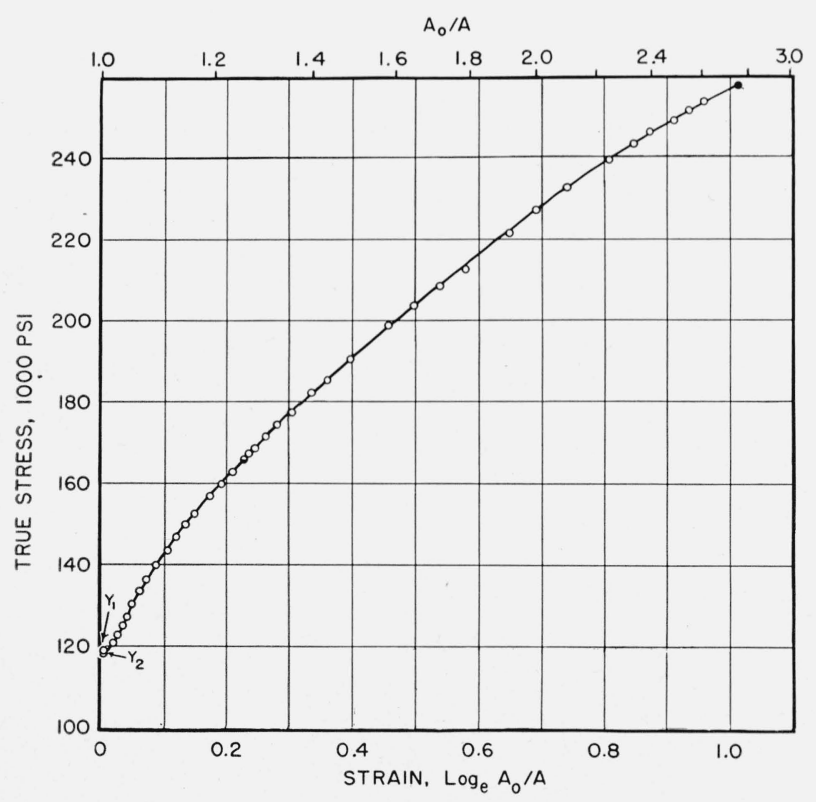

Figure 5. True stress-strain curve for a specimen of coldworked nickel tested in tension at $-188^{\circ} \mathrm{C}$.

$\mathrm{Y}_{1}$, upper yield; $\mathrm{Y}_{2}$, lower yield; $\bullet$, maximum load, $\bullet$, fracture.

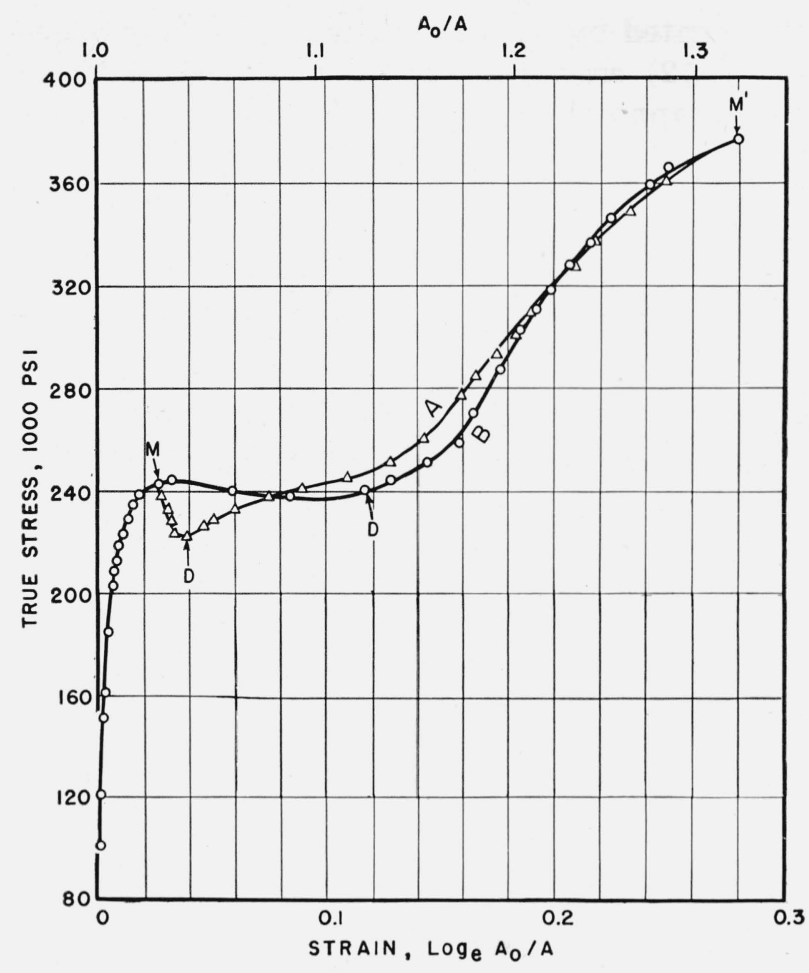

Figure 6.-Portion of the stress-strain curves for a specimen of cold-drawn (49\% reduction of area) 18:8 chromiumnickel steel, "EBM", tested in tension at $-196^{\circ} \mathrm{C}$.

Curve A, based on extension measurements; curve B, based on diameter measurements; D, minimum load, $\mathbf{M}$, first maximum load, $\mathbf{M}^{\prime}$, final maximum load.

The determination of true stress-true strain curves in cases where local contraction occurs before the load reaches a final maximum value is also possible by the use of this instrument, as illustrated by the results given in figure 6 . Portions of the curves from the points representing initial yielding to the final maximum load, as obtained by two different types of measurements during a tension test with a cold-worked 18:8 chromium-nickel steel at $-196^{\circ} \mathrm{C}$, are shown in this figure. Curve $A$ is based upon measurements of the extension of the specimen during the test as obtained from the automatic load-extension chart and on the assumption that the specimen remains cylindrical (no local contraction) with deformation to the final maximum load, represented by the point $M^{\prime}$. The actual true stresstrue strain curve determined from the change in diameter of the same specimen during the tension test as measured with this gage is shown as curve $B$. Curve $B$ shows that the local contraction at 
the minimum load, represented by point $D$ (true strain of approximately 0.12 ) corresponds to an actual reduction of area of approximately 11 percent whereas the curve $A$ based on extension measurements, indicates an apparent true strain of about 0.04 , corresponding to a reduction of area of approximately 4 percent. Thus curves $A$ and $B$ are not quantitatively similar.

\section{Summary}

A reduction-of-area gage was designed and constructed for measuring the change in diameter of test specimens submerged in liquid baths during tension tests at temperatures within the range of $-196^{\circ}$ to $+100^{\circ} \mathrm{C}$. The performance of the gage has been very satisfactory, as indicated by the test results shown for ingot iron, cold-worked nickel and 18:8 chromium-nickel steel.

The authors gratefully acknowledge the assistance of Mrs. F. A. Wilkinson and Miss L. B. Weinrich in the experimental testing and the preparation of illustrations, and the assistance of H. S. Miller of the Shop Division in the construction of the gage. 